Review Article

\title{
Depression and Psychological Trauma: An Overview Integrating Current Research and Specific Evidence of Studies in the Treatment of Depression in Public Mental Health Services in Chile
}

\author{
Verónica Vitriol, ${ }^{1,2}$ Alfredo Cancino, ${ }^{3,4}$ Kristina Weil, ${ }^{5}$ Carolina Salgado, ${ }^{6,7}$ \\ Maria Andrea Asenjo, ${ }^{8}$ and Soledad Potthoff ${ }^{6,7}$ \\ ${ }^{1}$ Department of Psychiatry, Medical School, Universidad de Talca, Chile \\ ${ }^{2}$ Mental Unit Hospital de Curicó, Curicó, Chile \\ ${ }^{3}$ Communal Mental Health Program, Communal Health Department of Curicó, Chile \\ ${ }^{4}$ Mental Health Formative Practices, Medical School, Universidad de Talca, Chile \\ ${ }^{5}$ Department of Psychiatry, Medical School, Universidad de los Andes, Santiago de Chile, Chile \\ ${ }^{6}$ Department of Psychiatry, Universidad de Talca, Chile \\ ${ }^{7}$ Mental Health Unit, Hospital de Talca, Chile \\ ${ }^{8}$ Mental Health Unit, CESFAM Curicó-Centro, Curicó, Chile \\ Correspondence should be addressed to Verónica Vitriol; vvitriol@utalca.cl
}

Received 30 July 2013; Revised 2 November 2013; Accepted 18 November 2013; Published 17 February 2014

Academic Editor: Frans G. Zitman

Copyright (C) 2014 Verónica Vitriol et al. This is an open access article distributed under the Creative Commons Attribution License, which permits unrestricted use, distribution, and reproduction in any medium, provided the original work is properly cited.

\begin{abstract}
In the last two decades, different research has demonstrated the high prevalence of childhood trauma, including sexual abuse, among depressive women. These findings are associated with a complex, severe, and chronic psychopathology. This can be explained considering the neurobiological changes secondary to early trauma that can provoke a neuroendocrine failure to compensate in response to challenge. It suggests the existence of a distinguishable clinical-neurobiological subtype of depression as a function of childhood trauma that requires specific treatments. Among women with depression and early trauma receiving treatment in a public mental health service in Chile, it was demonstrated that a brief outpatient intervention (that screened for and focused on childhood trauma and helped patients to understand current psychosocial difficulties as a repetition of past trauma) was effective in reducing psychiatric symptoms and improving interpersonal relationships. However, in this population, this intervention did not prevent posttraumatic stress disorder secondary to the extreme earthquake that occurred in February 2010. Therefore in adults with depression and early trauma, it is necessary to evaluate prolonged multimodal treatments that integrate pharmacotherapy, social support, and interpersonal psychotherapies with trauma focused interventions (specific interventions for specific traumas).
\end{abstract}

\section{Introduction}

Depression is a major cause of morbidity worldwide [1]. One of the risk factors that is associated with the development of this illness and its increased clinical severity is the exposure to early traumatic events [2].

Standardized clinical classifications such as the Diagnostic and Statistical Manual of Mental Disorders (DSM) and the International Classification Disease (ICD) have postulated a single unipolar depression $[3,4]$. Nevertheless, there is clinical and neurobiological evidence that suggests a distinguishable subtype of depression as a function of childhood trauma that ought to require specialized treatments [5].

Most of the approaches related to trauma have considered Posttraumatic stress disorder (PTSD) as the main diagnosis [6]. However, depression is two times more prevalent than PTSD in the general population [7]. Even though both pathologies are very often present in comorbidity [8], the 
study of depression as a result of trauma exposure is scarce. This area needs more attention, not only in trauma research but also in public mental health policies.

In Chile, like in many other countries, there is a legally mandated program to treat depression in mental health services, but the clinical guidelines do not include specifications regarding the approach to patients with depression and childhood trauma $[9,10]$.

Since 2002, our team has developed successive research on the prevalence of early trauma in adult patients with depression who are being treated through the primary care and/or secondary specialized care of the Public Health Service in Región del Maule. (The region is located $180 \mathrm{Km}$ south of Santiago, the capital of Chile.)

The objectives of this paper are

(1) to summarize the epidemiological and clinical findings in adults with depression and childhood trauma in treatment in the Mental Health Services in Chile,

(2) to further understand the risk factors that explain the relation between depression and psychological trauma,

(3) to integrate these findings in a model of treatment.

\section{Epidemiological Aspects}

During the past decade, international studies showed that over $50 \%$ of the general population has been exposed to psychological trauma $[11,12]$. In USA, $61 \%$ of men and $51 \%$ of women have been exposed to potentially traumatic events $[12,13]$. In Chile, $41.7 \%$ of men and $33.2 \%$ of women have had this previous reference [14].

While men are more exposed to noninterpersonal trauma, women are seriously affected by interpersonal trauma, of which physical and sexual events are the most common [12-14]. In these cases, polytrauma is more frequent than single trauma [14]. Despite the high prevalence of trauma in the general population, not all exposed persons develop a mental disorder related to the trauma [12]. Female gender, interpersonal trauma, and childhood trauma constitute risk factors associated with the further development of psychopathology $[15,16]$.

A series of epidemiological studies has demonstrated that childhood abuse is associated with a range of psychiatric disorders in adulthood that includes mood, anxiety, and substance abuse disorders [17].

PTSD is the most studied diagnosis as a result of trauma, including early traumatic experiences [6]. However, there is strong evidence demonstrating that emotional neglect as well as physical and sexual abuse during childhood constitutes risk factors in the development of depression in adulthood [2, 18-20] not only in one depressive episode but in its recurrence [21].

Depression is two times more prevalent than PTSD in the general population, being a major cause of morbidity worldwide. In most countries, the number of people who will suffer from depression during their lives falls within an $8 \%-12 \%$ range [1]. According to the World Health Organization, in
2004 unipolar depressive disorders were ranked as the third leading cause of the global burden of disease and they will move to the first place by 2030 [22].

In the past decade, in Chile, according to an epidemiologic study, using the Composite Diagnostic International Interview (CIDI), the prevalence of major depression and PTSD was $9 \%$ and $4.4 \%$, respectively [23]. Both pathologies were affecting twice the number of women than men. Recent studies have found that $17.7 \%$ of the general population has had depressive symptoms in the last year, with $25.5 \%$ occurring just in women [24].

It is also known that one-third of Chilean adults have been exposed at least to one psychological trauma during their lives [14] and, according to a recent UNICEF report, 71\% of children of 14 years old referred to having experienced some form of violence by their parents. Of them, $25.9 \%$ experienced severe physical violence and $8.7 \%$ sexual abuse [25].

Though depression, since 2006, was incorporated in the then newly mandated law, Garantías Explícitas en Salud (GES), and government economic support was included to treat this pathology [26], the importance of early trauma on depression has not been sufficiently studied in the Chilean population [27]. In 2001, when the national program to treat depression had been promoted, the study conducted by Alvarado found that risk factors associated with depression among women being treated by primary care in Santiago of Chile were one previous depressive episode, social isolation and low social support, severe family dysfunction, and a family history of suicide or attempts of suicide. Of them, low social support and suicide among relatives were statistically associated with more severity [27]. Nevertheless, in this study, record of childhood trauma was not investigated as a risk factor for developing depression.

Since 2002, in Región del Maule, we have focused our research on the prevalence of early trauma in adult patients with depression which in treatment at the primary care and secondary specialized care [28-30]. All these studies have used the Marshall scale [31]. This scale is a screening that inquires whether an individual has memories of having one or more of the following traumatic experiences before the age of 15: traumatic separation from a parent or caregiver, alcohol or drug abuse by a family member, physical violence between parents or caregivers, systematic punishment by parent or caregiver, physical injury associated with punishment, and/or forced sexual contact with a relative or a nonrelative. In these studies, which were conducted in different clinical samples, we founded a range of prevalence between $52.1 \%$ and $87.5 \%$ of psychiatric patients who recalled at least one of the childhood traumatic events [28-30] (Table 1).

Two of these investigations were specifically developed in patients with depression. One of them studied 442 women with mild and moderate depression treated in the primary care program [29]. The other one studied 130 women with severe depression treated in the secondary specialized care program [28]. In both studies, according to the Marshall scale, the most frequently recalled event was alcohol or drug abuse by a family member, which was found to be $48.2 \%$ and $67.7 \%$, respectively. The second most frequent recalled event was a traumatic separation from a parent or caregiver and 
TABLE 1: Prevalences of childhood trauma among general morbidity patients and psychiatric patients in Chile.

\begin{tabular}{|c|c|c|c|}
\hline Place/authors & Sample & $\begin{array}{l}\text { At least one item in } \\
\text { Marshall scale }^{*}\end{array}$ & $\%$ sexual abuse \\
\hline $\begin{array}{l}4 \text { General hospitals } \\
\text { (Weil et al., } 2004[30] \text { ) }\end{array}$ & $\begin{array}{l}505 \text { general medicine patients, } \\
\text { both genders ( } 263 \text { men and } 242 \text { women) }\end{array}$ & $54.7 \%$ & $6.8 \%$ \\
\hline $\begin{array}{l}\text { Hospital Curico } \\
\text { (Vitriol et al., } 2006 \text { [28]) }\end{array}$ & 130 women ingressed for severe depression & $87.5 \%$ & $42 \%$ \\
\hline $\begin{array}{l}\text { CES Curico-Centro } \\
\text { (Cancino and Asenjo, } 2006 \\
{[29] \text { ) }}\end{array}$ & $\begin{array}{l}510 \text { patients ( } 442 \text { women and } 68 \text { men) } \\
\text { ingressed for nonsevere depression }\end{array}$ & $84 \%$ & $38.8 \%$ \\
\hline $\begin{array}{l}\text { Hospital TALCA } \\
\text { (Salgado, Potthoff, 2012) } \\
\text { unpublished observation } \\
\text { presented at the 21st World } \\
\text { Congress for Social Psychiatry, } \\
\text { Lisbon, Portugal, } 2013\end{array}$ & $\begin{array}{l}593 \text { psychiatric patients } \\
\text { ( } 453 \text { women and } 140 \text { men) }\end{array}$ & $52.1 \%$ & $35.2 \%$ \\
\hline
\end{tabular}

was determined to be between $40 \%$ and $50 \%$ of the patients. The third most frequent being the systematic punishment by a parent or a caregiver and was reported in $36 \%$ of primary care patients and $61 \%$ of secondary specialized care patients. Furthermore, $38.8 \%$ of the primary care group and $42 \%$ of the secondary care group with severe depression mentioned they had experienced sexual abuse during childhood.

In the previously referenced study involving 130 women with severe depression, using the CIDI, we found the prevalence of PTSD to be $49.2 \%$ [32]. When the prevalence of PTSD was considered in relation to the number of affirmative answers on the Marshall scale, the prevalence was an increasing function of the number of childhood traumatic events reported by the patients [32]. When comparing patients with three or more childhood traumatic events in relation to those who had less than three of these events, the application of CIDI indicated a higher average of exposure to traumatic events during adulthood (3.87 versus 2.15; $t=5.014 ; P<$ 0.001 ) and an earlier age of exposure to the most traumatic event (17 versus 27 years old). Likewise, in these patients it was found that the accidents, sexual harassment, rape, or physical aggression was the most significant CIDI event associated with their pathology [32].

In 2010, in another study conducted in the secondary care program, we observed the prevalence of posttraumatic symptoms among 75 women in treatment for severe depression who had experienced the megaearthquake on F-27. After six months $53 \%$ of the patients demonstrated PTSD related to the disaster [33], twice that which occurred in the general population exposed to this disaster [34]. Early trauma and acute stress disorder were the risk factors associated with the postcatastrophe PTSD in these patients [33].

These results indicate the high prevalence of childhood trauma, including emotional, physical, and sexual abuse, in patients who are in treatment for depression at public mental health services in Region del Maule, Chile [28, 29]. These findings are associated with greater severity of symptoms and comorbidity. In accordance to these results, it should be necessary to actively question patients with depressive symptoms about their childhood trauma history, in order to determine comorbidity and, hence, to design specific strategies for treatment.

\section{Neurobiological Factors That Link Childhood Trauma to Adult Depression}

There is strong evidence that childhood trauma is associated with a several neurobiological findings, which may configure the diathesis for adulthood psychopathology [35].

Childhood trauma is associated with sensitization of the neuroendocrine and autonomic stress response, glucocorticoid resistance, increased central corticotropin-releasing factor (CRF) activity, immune activation, and reduced hippocampal volume. A major focus of investigation in this area has been the role of the hypothalamic-pituitary-adrenal (HPA) axis, both as a marker of the stress response and as a mediator of additional downstream pathophysiologic changes. The HPA axis functions in close concert with the Locus Coeruleus-Norepinephrine (LC-NE) system, which is involved in extensive reciprocal innervation of regions throughout the central nervous system (CNS) $[36,37]$.

The dysregulation of HPA axis also involves changes in the pituitary responsiveness to CRF stimulation suggesting changes of CRF receptors due to alterations in the activity of the paraventricular nucleus (PVN-) median eminence CRF circuit. This impairment of physiological adjustment is shown by an increased and blunted adrenocorticotropic hormone (ACTH) response to corticotropin releasing hormone $(\mathrm{CRH})$ stimulation [37].

In clinical samples, Heim et al. report that women with a history of child abuse with major depression showed significantly increased cortisol responses to psychological stress as compared with healthy control subjects and abused women without depression. In ( $\mathrm{CRH})$ stimulation tests among these women, those with a history of childhood abuse without 
depression exhibited increased ACTH responses along with normal-to-decreased cortisol responses. In contrast, women with a history of childhood abuse with comorbid major depression exhibited blunted ACTH responses, likely due to chronic overexposure of the pituitary to $\mathrm{CRH}$. These findings suggest that there may be an initial sensitization of the stress hormone system during early life adversity, representing a biological vulnerability for the development of depression and anxiety disorders in later life [38].

In another study, these same investigators examined 66 women divided into four groups: (1) healthy without early life stress $(\mathrm{H})$ (2) history of childhood abuse without major depression (CA) (3) history of childhood abuse and current major depressive disorder (CAMDD) (4) current major depressive disorder but no early life stress (MDD). Plasma $\mathrm{ACTH}$ and cortisol responses to ovine CRH $1 \mu \mathrm{g} / \mathrm{kg}$ and plasma cortisol responses to ACTH $250 \mu \mathrm{g}$ were measured. In comparison with the $\mathrm{H}$ group, $\mathrm{CA}$ subjects exhibited enhanced ACTH responses to $\mathrm{CRH}$ administration, whereas the CAMDD and MDD groups demonstrated blunted ACTH responses; cortisol responses to $\mathrm{CRH}$ were blunted in the CAMDD and CA groups relative to the $\mathrm{H}$ group. In the ACTH stimulation test, the CA group exhibited lower baseline and stimulated plasma cortisol concentrations than the $\mathrm{H}$ subjects, whereas the CAMDD group showed lower baseline cortisol levels only. These findings also support the etiological hypothesis that depression and anxiety in these women are related to stress exposure later in life resulting in hypersecretion of $\mathrm{CRH}$ and downregulation of adenohypophyseal $\mathrm{CRH}$ receptors [39].

Another neurobiological mechanism altered by early trauma is in relation to the neuropeptide oxytocin (OT). This neuropeptide has an important role in mediating social affiliation, mother-child attachment, social support, and trust. Further, OT has stress-protective effects and decreases amygdala reactivity in humans [40]. Evidence shows a decreased OT level in central nervous system in patients with history of childhood trauma. These results support the hypothesis that early adverse experience may interfere with the development of brain systems implicated in social attachment, which may then lead to decreased resilience against stress and anxiety [41].

The most available evidence suggests that the pathways affected in subjects with a history of childhood maltreatment are predominantly in frontolimbic networks, including medial prefrontal cortex (mPFC), orbitofrontal cortex (OFC), anterior cingulate cortex (ACC), hippocampus, and amygdala. These pathways are involved in emotion and motivation processing, as well as the control of aggression. Disruption to these pathways in abused subjects may, therefore, underlie the observed deficits in emotion and reward processing as well as excessive aggression or violent behavior. Deficits in these frontolimbic networks may be due to the vulnerability of the frontal lobe to stress effects due to the fact that it has a high density of glucocorticoid receptors and dopaminergic projections that are stress susceptible [42].

It is very important to consider sex differences in the neurobiological findings associated with childhood trauma [43]. It is well known that sex steroids interact with other neurotransmitter systems involved in the stress response, such as the serotonin system. Estrogen receptor mRNA has been localized in parvocellular CRH neurons of the paraventricular nucleus of hypothalamus (PVN) and there is evidence for an estrogen-responsive portion of the promoter region of the human CRF gene, which confers estrogen enhancement of CRF expression in CV-1 transfected cells [44]. Progesteron has also been implicated in modulating these systems involved in stress response. However, it has been observed that women exhibit greater magnitude and duration of HPA axis responses to stress than men independent of acute gonadal steroid effects. Other factors that might determine sex differences in the stress response include genomic differences, organizational differences in brain structures, or developmentally programmed effects of gonadal steroids. In addition, sex steroids play a role in lifelong structural plasticity of several brain regions, including areas involved in stress responsiveness, like hippocampus and amygdala [45].

The effects of childhood trauma on later vulnerability to stress and disease are also moderated by genotype [46]. The serotonin transporter gene 5 HTTLPR significantly moderates the effects of stressful life events on depression. The carrier $\mathrm{L} / \mathrm{L}$ is resilient to the depressogenic effect of life stress so the s/s predisposes to depression [47]. Depression risk as a function of child mistreatment and 5 HTTLPR status is further modified by social support and a polymorphism in the brain-derived neurotrophic factor (BDNF) [48].

Another gene involved in the relation between childhood trauma and adult depression is the CRH Receptor-1 (CRHR1) gene. This gene moderates the effects of specific types of childhood trauma on depression and explains the relation between female gender, sexual abuse, and adult depression [49].

These neurobiological changes secondary to early trauma can provoke a neuroendocrine failure to compensate the response to challenge and reflect a risk to develop depression in response to stress in adult life. It suggests the existence of biologically distinguishable subtype of depression as a function of childhood trauma [38].

\section{Clinical Considerations}

Childhood trauma promotes the development of a spectrum of psychiatric and medical disorders [17]. This includes anxiety disorders [50], somatization disorder [30], PTSD [6], personality disorders [51], depression [52], alcohol and drugs abuse [53], eating disorders [54], chronic fatigue syndrome [55], fibromyalgia [56], functional gastrointestinal disorders [57], and cardiovascular diseases [58].

An important comorbidity related to childhood trauma is the association with anxiety, depressive, and somatoform symptoms [59]. These comorbidities often present in general medical patients are associated with more expensive costs in health resources [60-62]. In our country, among 505 medical inpatients in four general hospitals, we found a high exposure to childhood trauma, which was associated with PTSD, somatization disorder, depression, and personality disorder [30]. 
TABLE 2: Average scores in Hamilton, OQ 45 and PTO 8 between 81 women with severe depression and childhood trauma and 49 women with severe depression and without childhood trauma [77].

\begin{tabular}{|c|c|c|c|c|c|c|}
\hline Test & Average with trauma & DS & Average without trauma & DS & $T$ & $P$ \\
\hline Marshall $^{1}$ & 4.17 & 1.34 & 1.57 & 1.37 & 10.32 & 0.01 \\
\hline Hamilton $\mathrm{D}^{2}$ & 34.67 & 6.24 & 24.02 & 9.57 & 7.59 & 0.01 \\
\hline OQ 1 total $^{3}$ & 115.04 & 20.0 & 84.84 & 31.6 & 6.58 & 0.01 \\
\hline OQ symptoms ${ }^{4}$ & 73.08 & 12.2 & 56.57 & 20.9 & 5.63 & 0.01 \\
\hline OQ Interpers. Rel. ${ }^{5}$ & 24.08 & 6.59 & 15.86 & 8.63 & 6.005 & 0.01 \\
\hline OQ 1 Social role ${ }^{6}$ & 18.02 & 6.06 & 12.09 & 6.61 & 5.096 & 0.01 \\
\hline PTO $8^{7}$ & 18.00 & 8.17 & 8.18 & 8.85 & 6.264 & 0.01 \\
\hline
\end{tabular}

${ }^{1}$ Marshall scale: scores between 0 and 7 points according to childhood trauma events.

${ }^{2}$ Hamilton depression scale: scores between 0 and 63 points with higher scores indicating a greater severity of symptoms.

${ }^{3} \mathrm{OQ} 45$ global scale: scores between 0 and 180 points with higher scores indicating worse function.

${ }^{4} \mathrm{OQ} 45$ symptoms scale: scores between 0 and 100 points with higher scores indicating a greater severity of symptoms.

${ }^{5} \mathrm{OQ} 45$ interpersonal scale: scores between 0 and 44 points with higher scores indicating worse function.

${ }^{6} \mathrm{OQ} 45$ social role scale: scores between 0 and 36 points with higher scores indicating worse function.

${ }^{7} \mathrm{PTO} 8$ scale: scores between 0 and 32 points with higher scores indicating a greater severity of symptoms.

As previously mentioned, depressive disorders and PTSD occur very often in comorbidity $[63,64]$. They share common risk factors such as female gender and history of childhood trauma [65]. Each one is a factor of vulnerability for the development of the other one [63]. In addition, the PTSDdepression comorbidity has been associated with increased clinical severity, suicidality, chronicity, and greater spending on health resources [66-69]. Even though, this pathology is underdiagnosed in clinical patients [70].

There is evidence that, in patients with a history of childhood trauma, PTSD is more complex, correlated with personality disorders, particularly superimposed on borderline personality disorder [71]. These patients often present anxiety and depressive symptoms, alterations in emotional regulation, and revictimization phenomena [72]. Considering these findings it is postulated that patients with early trauma should receive a special category "complex PTSD," joining axes I and II of DSM classification, and they should be considered differently from borderline patients [73].

Patients with depression and early trauma also show major symptomatic severity, increased risk of suicidality, and interpersonal difficulties [74-76]. In the same sample of 130 women evaluated in Curicó, it was shown, using several scales to evaluate symptomatic severity, that women with severe depression and early trauma had significant severity in depressive symptoms, PTSD symptoms, and interpersonal difficulties (Table 2) [77]. In this study, patients with early trauma had twice the number of suicide attempts than those severely depressed women without early trauma history [77]. We did not evaluate personality disorder but these findings suggest that these patients have the same clinical picture as described in patients with complex PTSD.

Another relevant clinical aspect described in women with a history of sexual abuse is the revictimization phenomenon throughout their lives, including transgenerational transmission of the psychological trauma $[79,80]$. Most of women with previous sexual abuse events have a history of recurrent rape and traumatization. They also have repressed and silent suffering in all aspects of their lives and the abuse is still seriously affecting them and their loved ones including their children [81]. These aspects were also observed by us in our patients $[82,83]$. The patients had been using the public health service to a great extent, but not getting adequate help and indeed many times they had been mistreated by the medical staff (referred on, postponed, or rejected) [84]. The traumatic background is not routinely inquired about when these patients are interviewed when they seek medical help [85].

In brief, in our region, we correlated that patients with depression and childhood trauma show a complex, severe, and chronic psychopathology. These findings suggest the existence of a clinical distinguishable subtype of depression as a function of childhood trauma that requires specific treatments.

\section{Treatment Approaches}

In spite of evidence that patient with childhood trauma present a neurobiological clinical subtype of depression, its management is not recommended enough in clinical guidelines [10].

Research examining the effects of childhood trauma on treatment response in depression is limited. One study found that patients with chronic depression and early trauma respond better to psychotherapy alone versus pharmacotherapy [86]. Another three studies showed that nonresponsiveness to antidepressant medication was associated with childhood abuse in both outpatients and inpatients settings [87-89]. There is a need to develop modes of treatment for patients with depression and having a history of childhood abuse and furthermore a need to evaluate their effectiveness.

Considering the psychotherapies with empirical evidence to treat depression, interpersonal psychotherapy (IPT) is one of the most relevant at this point. IPT is a time-limited psychotherapy that focuses on social and interpersonal problems in the patient's current life, for understanding and treating symptoms [90]. 
TABLE 3: Symptoms changes over time among 87 severe depressive women with childhood trauma, 44 of them assigned to protocolized interpersonal model of trauma (IMT) versus 43 who received usual treatment. Curicó, Chile [78].

\begin{tabular}{|c|c|c|c|c|c|c|}
\hline \multirow{2}{*}{ Outcome measures and groups } & \multicolumn{2}{|c|}{ Admission } & \multicolumn{2}{|c|}{ Discharge } & \multicolumn{2}{|c|}{6 months follow up } \\
\hline & Mean & $(\mathrm{SD})$ & Mean & $(\mathrm{SD})$ & Mean & $(\mathrm{SD})$ \\
\hline \multicolumn{7}{|l|}{ Hamilton $^{1}$} \\
\hline Protocol group & 34.09 & 6.2 & 22.1 & $8.8^{*}$ & 19.4 & $8.8^{* *}$ \\
\hline Control group & 34.42 & 6.7 & 27.5 & 9.7 & 25.0 & 11.1 \\
\hline \multicolumn{7}{|l|}{ OQ45 total ${ }^{2}$} \\
\hline Protocol group & 112.73 & 19.7 & 92.7 & $28.3^{*}$ & 85.8 & $37.6^{*}$ \\
\hline Control group & 114.72 & 22.5 & 105.4 & 31.0 & 102 & 31.7 \\
\hline \multicolumn{7}{|l|}{ OQ45 symptoms ${ }^{3}$} \\
\hline Protocol group & 71.07 & 12.2 & 59.1 & 18.4 & 53.5 & $22.8^{*}$ \\
\hline Control group & 73.37 & 13.6 & 65.6 & 17.0 & 63.4 & 18.9 \\
\hline \multicolumn{7}{|l|}{ OQ45 Interpers. Rel. ${ }^{4}$} \\
\hline Protocol group & 24.5 & 6.6 & 19.0 & 7.7 & 18.7 & 10.2 \\
\hline Control group & 23.1 & 6.9 & 22.6 & 11.1 & 21.6 & 8.7 \\
\hline \multicolumn{7}{|l|}{ OQ45 social ${ }^{5}$} \\
\hline Protocol group & 17.4 & 5.5 & 14.5 & 6.8 & 13.5 & $8.2^{*}$ \\
\hline Control group & 18.3 & 6.7 & 17.1 & 7.9 & 16.8 & 7.1 \\
\hline \multicolumn{7}{|c|}{ Posttraumatic symptoms scale (PTO- 8$)^{6}$} \\
\hline Protocol group & 16.6 & 7.6 & 12.6 & 7.8 & 11.7 & 7.9 \\
\hline Control group & 19.1 & 8.4 & 14.9 & 8.1 & 15.0 & 7.8 \\
\hline
\end{tabular}

${ }^{1}$ Hamilton: scores between 0 to 63 points with higher scores indicating a greater severity of symptoms.

${ }^{2} \mathrm{OQ} 45$ global scale: scores between 0 to 180 points with higher scores indicating worse function.

${ }^{3} \mathrm{OQ} 45$ symptomatic scale: scores between 0 to 100 points with higher scores indicating a greater severity of symptoms.

${ }^{4} \mathrm{OQ} 45$ interpersonal scale: scores 0 to 44 points with higher scores indicating worse function.

${ }^{5}$ OQ45 social role scale: scores between 0 to 36 points with higher scores indicating worse function.

${ }^{6}$ PTO 8 scale: scores between 0 to 32 points with higher scores indicating a greater severity of symptoms.

${ }^{*}<0.005,{ }^{* *}<0.001$.

There is evidence that patients with early trauma often seek care due to interpersonal problems, especially revictimization phenomena [91, 92]. These interpersonal difficulties can be understood considering the neurobiological consequences of psychological trauma [93]. But also, these difficulties can be understood from the psychoanalysis paradigm, considering the concept of compulsion to repeat the trauma [94-96].

Linking the evidence of IPT in treating depression and the compulsion to repeat the trauma to understand interpersonal difficulties among patients with early trauma, we organized a model of intervention that we call IMT (interpersonal model to treat patients with depression and childhood trauma history) [97].

It is relevant to consider that, in the first interview, early trauma and interpersonal difficulties in patients with depression are inquired about. Then, this model provides a focus on a current dysfunctional interactional pattern associated with depression, in which aggression and victimization are at the center. Such a pattern is understood as a repetition of childhood traumatic experiences. The intervention focuses on developing a cognitive understanding of personal characteristics and behavior allowing the repetition of traumatic experiences in the present. The goal of the intervention is to discriminate the present from the past, avoid the revictimization, and promote the devictimization [97].
During 2006, we evaluated this model associated with pharmacotherapy in a three-month structured intervention, comparing 44 women treated by IMT with 43 women treated as usual. They were evaluated at baseline, at the third and sixth months, with the Hamilton scale for depression (Ham$\mathrm{D})$, the Lambert questionnaire (OQ-45.2) (which includes the social and interpersonal subscales), and the eight-item questionnaire (PTO-8) to evaluate PTSD symptoms. At three months, significant differences were found in favor of the intervention group in Ham-D scores $(P<0.01)$ and in OQ-45.2 scores $(P<0.05)$. In OQ-45 social subscale, we only found clinical differences in favor of IMT at the sixth month. In OQ-45 interpersonal subscale, only the IMT group obtained significant improvement. In PTO-8 there were no significant differences between both groups (Table 3) [78].

If we consider remission as the goal of the treatment of depression, only $22 \%$ of the intervention group attained the goal (versus 5.6\% in control group) [78].

We demonstrated that the proposed intervention was more effective than the usual treatment in patients with depression and childhood trauma history. However, the intervention group persisted with symptomatic and dysfunctional indicators at the end of the observation. These findings might be explained through brevity of intervention and suggest more evidence that these patients need prolonged multimodal treatments [98]. 
But, what kind of prolonged multimodal treatment do these patients need? A prolonged interpersonal model [99101] or an interpersonal model integrated with a trauma focused model [102]? Why do we ask this?

In 2010, we observed the evolution of 75 women in treatment for depression who experienced the megaearthquake in Chile, $75 \%$ of them had history of childhood abuse. Although they continued with an intensive pharmacological and interpersonal support treatment very soon after the disaster, six months later 53\% of them showed PTSD according to ICD. The intervention helped the women by the sixth month to improve their clinical global impression, thus, avoiding hospitalization and preventing suicide attempts [103]. These results suggest that these patients would require specific trauma focused interventions immediately after a disaster of this magnitude to prevent PTSD [103].

So, we need to investigate not only prolonged interpersonal treatment in patients with depression and a record of psychological trauma [99-101] but also the effectiveness of specific trauma focused interventions in patients who seek care and the principal diagnosis is depression, mainly when there is a comorbidity with PTSD [102], for example, using exposure therapy in a second step $[104,105]$ or prescribing other medication like propranolol [106].

In summary, patients with depression and history of interpersonal psychological trauma since childhood have a complex profile, so they need to be structured in a program that addresses its many complexities and not only the depressive symptoms.

\section{Conflict of Interests}

The authors declare that there is no conflict of interests regarding the publication of this paper.

\section{Acknowledgment}

This symposium was presented at the 21st World Congress for Social Psychiatry, Lisbon, Portugal, 2013.

\section{References}

[1] WHO, "Depression," Fact sheet no. 369, 2012, http://www.who .int/mediacentre/factsheets/fs369/es/index.html.

[2] K. S. Kendler, J. W. Kuhn, and C. A. Prescott, "Childhood sexual abuse, stressful life events and risk for major depression in women," Psychological Medicine, vol. 34, no. 8, pp. 1475-1482, 2004.

[3] Diagnostic and Statistics Manual of Mental Disorders, vol. DSMIV-TR, American Psychiatry Association, 2000.

[4] WHO International Classification of Diseases: Clinical Descriptions and Diagnostic Guidelines, Ediciones Meditor, Madrid, Spain, 1992, (Spanish).

[5] E. L. Weiss, J. G. Longhurst, and C. M. Mazure, "Childhood sexual abuse as a risk factor for depression in women: psychosocial and neurobiological correlates," American Journal of Psychiatry, vol. 156, no. 6, pp. 816-828, 1999.
[6] H. Javidi and M. Yadollahie, "The post-traumatic stress disorder," The International Journal of Occupational and Environmental Medicine, vol. 3, no. 1, pp. 2-9, 2012.

[7] R. C. Kessler, W. T. Chiu, O. Demler, K. R. Merikangas, and E. E. Walters, "Prevalence, severity, and co-morbidity of 12month DSM-IV disorders in the National Comorbidity Survey Replication," Archives of General Psychiatry, vol. 62, no. 6, pp. 617-627, 2005.

[8] F. Ducrocq, G. Vaiva, O. Cottencin, S. Molenda, and D. Bailly, "Post-traumatic stress disorder, post-traumatic depression and major depressive disorder: about literature," Encephale, vol. 27, no. 2, pp. 159-168, 2001.

[9] M. Marcus, M. van Ommeren, and D. Chisholm, Depression: A Global Public Health Concern, WHO Department of Mental Health and Substance Abuse, World Health Organization, Geneva, Switzerland, 2012.

[10] Gobierno de Chile, Ministerio de Salud, Guía Clínica Tratamiento Personas con Depresión, 2013.

[11] R. C. Kessler, A. Sonnega, E. Bromet, M. Hughes, and C. B. Nelson, "Posttraumatic stress disorder in the national comorbidity survey," Archives of General Psychiatry, vol. 52, no. 12, pp. 10481060, 1995.

[12] N. Breslau, R. C. Kessler, H. D. Chilcoat, L. R. Schultz, G. C. Davis, and P. Andreski, "Trauma and posttraumatic stress disorder in the community: the 1996 Detroit area survey of trauma," Archives of General Psychiatry, vol. 55, no. 7, pp. 626632, 1998.

[13] N. Breslau, "Epidemiologic studies of trauma, posttraumatic stress disorder, and other psychiatric disorders," Canadian Journal of Psychiatry, vol. 47, no. 10, pp. 923-929, 2002.

[14] C. Zlotnick, J. Johnson, R. Kohn, B. Vicente, P. Rioseco, and S. Saldivia, "Epidemiology of trauma, post-traumatic stress disorder (PTSD) and co-morbid disorders in Chile," Psychological Medicine, vol. 36, no. 11, pp. 1523-1533, 2006.

[15] C. Pérez, B. Vicente, C. Zlotnick et al., "Estudio epidemiológico de sucesos traumáticos, trastorno de estrés post-traumático y otros trastornos psiquiátricos en una muestra representativa de Chile," Salud Mental, vol. 32, no. 2, pp. 145-153, 2009.

[16] C. Zlotnick, J. Johnson, R. Kohn, B. Vicente, P. Rioseco, and S. Saldivia, "Childhood trauma, trauma in adulthood, and psychiatric diagnoses: results from a community sample," Comprehensive Psychiatry, vol. 49, no. 2, pp. 163-169, 2008.

[17] R. E. Norman, M. Byambaa, R. De, A. Butchart, J. Scott, and T. Vos, "The long-term health consequences of child physical abuse, emotional abuse, and neglect: a systematic review and meta-analysis," PLOS Medicine, vol. 9, no. 11, Article ID e1001349, 2012.

[18] B. E. Gibb, A. C. Butler, and J. S. Beck, "Childhood abuse, depression, and anxiety in adult psychiatric outpatients," Depression and Anxiety, vol. 17, no. 4, pp. 226-228, 2003.

[19] B. E. Gibb, I. Chelminski, and M. Zimmerman, "Childhood emotional, physical, and sexual abuse, and diagnoses of depressive and anxiety disorders in adult psychiatric outpatients," Depression and Anxiety, vol. 24, no. 4, pp. 256-263, 2007.

[20] P. Spinhoven, B. M. Elzinga, J. G. F. M. Hovens et al., "The specificity of childhood adversities and negative life events across the life span to anxiety and depressive disorders," Journal of Affective Disorders, vol. 126, no. 1-2, pp. 103-112, 2010.

[21] D. P. Chapman, C. L. Whitfield, V. J. Felitti, S. R. Dube, V. J. Edwards, and R. F. Anda, "Adverse childhood experiences and the risk of depressive disorders in adulthood," Journal of Affective Disorders, vol. 82, no. 2, pp. 217-225, 2004. 
[22] C. Mathers, D. M. Fat, and J. T. Boerma, "The global burden of disease: 2004 update," Tech. Rep., World Health Organization, 2008.

[23] P. B. Vicente, S. P. Rioseco, B. S. Saldivia, R. Kohn, and P. S. Torres, "Estudio chileno de prevalencia de patología psiquiátrica (DSM-III-R/CIDI) (ECPP)," Revista Médica De Chile, vol. 130, no. 5, pp. 527-536, 2002.

[24] Informe Encuesta Nacional de Salud, ENS 2009-2011, Santiago, Chile, MINSAL, 2011.

[25] S. Larraín and C. Basuñan, IV Estudio De Maltrato Infantil, UNICEF, 2012.

[26] Gobierno de Chile, Ministerio de Hacienda, Garantías explicitas en salud, 2006.

[27] R. Alvarado and G. Rojas, "El programa nacional para el diagnóstico y tratamiento para la depresión en atención primaria: una evaluación necesaria," Revista Médica de Chile, vol. 139, no. 5, pp. 592-599, 2011.

[28] V. Vitriol, "Relación entre psicopatología adulta y antecedentes de trauma infantil," Revista Chilena de Neuro-Psiquiatría, vol. 43, no. 2, pp. 83-87, 2005.

[29] A. Cancino and M. Asenjo, "Antecedentes traumáticos infantiles en personas ingresadas al programa de depresión en el CES Curicó-Centro durante el año 2006," Universidad de Talca FACE- ESGS, año 3, no. 7.

[30] K. Weil, R. Florenzano, V. Vitriol et al., “Trauma infanto juvenil y psicopatología adulta: un estudio empírico," Revista Médica de Chile, vol. 132, no. 12, pp. 1499-1504, 2004.

[31] C. Cuneo, I. Gonzalez, M. Jara et al., "Validación externa de la Escala de Trauma de Marshall," in Trauma Infanto- Juvenil Y Psicopatología Adulta, R. Florenzano, P. Weil, C. Carvajal, and C. Cruz, Eds., Editorial Corporación de Promoción Universitaria, Santiago, Chile, 2005.

[32] V. Vitriol, S. Ballesteros, R. Florenzano, A. Calderón, A. Vacarezza, and D. Schwartz, "Relación entre trauma infantil y comorbilidad de depresión con trastorno de estrés postraumático," Revista de Trastornos del Ánimo, vol. 2, no. 1, pp. 101-108, 2008.

[33] V. Vitriol, A. Cancino, P. Riquelme, and I. Reyes, “Terremoto en Chile: estrés agudo y estrés postraumático en mujeres en tratamiento por depresión grave," Revista Médica de Chile, vol. 141, pp. 338-344, 2013.

[34] Ministerio de Planificación Gobierno de Chile, "Encuesta posterremoto," in Efectos en la Calidad de Vida de la Población Afectada por Terremoto/Tsunami, O. Larrañaga and R. Herrera, Eds., 2010.

[35] C. B. Nemeroff, "Neurobiological consequences of childhood trauma," Journal of Clinical Psychiatry, vol. 65, no. 1, pp. 18-28, 2004.

[36] A. D. A. Feijó de Mello, M. F. De Mello, L. L. Carpenter, and L. H. Price, "Update on stress and depression: the role of the hypothalamic-pituitary-adrenal (HPA) axis," Revista Brasileira de Psiquiatria, vol. 25, no. 4, pp. 231-238, 2003.

[37] C. Heim and C. B. Nemeroff, "The role of childhood trauma in the neurobiology of mood and anxiety disorders: preclinical and clinical studies," Biological Psychiatry, vol. 49, no. 12, pp. 1023-1039, 2001.

[38] C. Heim, D. J. Newport, T. Mletzko, A. H. Miller, and C. B. Nemeroff, "The link between childhood trauma and depression: insights from HPA axis studies in humans," Psychoneuroendocrinology, vol. 33, no. 6, pp. 693-710, 2008.
[39] C. Heim, D. J. Newport, R. Bonsall, A. H. Miller, and C. B. Nemeroff, "Altered pituitary-adrenal axis responses to provocative challenge tests in adult survivors of childhood abuse," American Journal of Psychiatry, vol. 158, no. 4, pp. 575-581, 2001.

[40] M. Olff, J. L. Frijling, L. D. Kubzansky et al., "The role of oxytocin in social bonding, stress regulation and mental health: an update on the moderating effects of context and interindividual differences," Psychoneuroendocrinology, vol. 13, no. 9, pp. 236-239, 2013.

[41] C. Heim, L. J. Young, D. J. Newport, T. Mletzko, A. H. Miller, and C. B. Nemeroff, "Lower CSF oxytocin concentrations in women with a history of childhood abuse," Molecular Psychiatry, vol. 14, no. 10, pp. 954-958, 2009.

[42] H. Hart and K. Rubia, "Neuroimaging of child abuse: a critical review," Frontiers in Human Neuroscience, vol. 6, article 52, 2012.

[43] M. Olff, W. Langeland, N. Draijer, and B. P. R. Gersons, "Gender differences in posttraumatic stress disorder," Psychological Bulletin, vol. 133, no. 2, pp. 183-204, 2007.

[44] B. M. Kudielka and C. Kirschbaum, "Sex differences in HPA axis responses to stress: a review," Biological Psychology, vol. 69, no. 1, pp. 113-132, 2005.

[45] K. S. Macdonald, "Sex, receptors and attachment: a review of individual factors influencing response to oxytocin," Frontiers in Neuroscience, vol. 6, article 194, 2012.

[46] Y. Auxéméry, "Posttraumatic stress disorder (PTSD) as a consequence of the interaction between an individual genetic susceptibility, a traumatogenic event and a social context," Encephale, vol. 38, no. 5, pp. 373-380, 2012.

[47] A. Caspi, K. Sugden, T. E. Moffitt et al., "Influence of life stress on depression: moderation by a polymorphism in the 5-HTT gene," Science, vol. 301, no. 5631, pp. 386-389, 2003.

[48] S. M. Monroe and M. W. Reid, "Gene-environment interactions in depression research: genetic polymorphisms and life-stress polyprocedures," Psychological Science, vol. 19, no. 10, pp. 947956, 2008.

[49] C. Heim, B. Bradley, T. C. Mletzko et al., "Effect of childhood trauma on adult depression and neuroendocrine function: sexspecific moderation by CRH receptor 1 gene," Frontiers in Behavioral Neuroscience, vol. 3, article 41, 2009.

[50] J. G. F. M. Hovens, J. E. Wiersma, E. J. Giltay et al., "Childhood life events and childhood trauma in adult patients with depressive, anxiety and comorbid disorders vs. controls," Acta Psychiatrica Scandinavica, vol. 122, no. 1, pp. 66-74, 2010.

[51] J. F. Alillaire, "Borderline personality disorder: diagnosis and treatment," Bulletin de l'Académie Nationale de Médecine, vol. 196, no. 7, pp. 1439-1458, 2012.

[52] R. Maniglio, "Child sexual abuse in the etiology of depression: a systematic review of reviews," Depression and Anxiety, vol. 27, no. 7, pp. 631-642, 2010.

[53] K. T. Brady and S. E. Back, "Childhood trauma, posttraumatic stress disorder, and alcohol dependence," Alcohol Research, vol. 34, no. 4, pp. 408-413, 2012.

[54] R. A. Sansone and L. A. Sansone, "Childhood trauma, borderline personality, and eating disorders: a development cascade," Eating Disorders, vol. 15, no. 4, pp. 333-346, 2007.

[55] C. Heim, D. Wagner, E. Maloney et al., "Early adverse experience and risk for chronic fatigue syndrome: results from a population-based study," Archives of General Psychiatry, vol. 63, no. 11, pp. 1258-1266, 2006.

[56] L. A. Low and P. Schweinhardt, "Early life adversity as a risk factor for fibromyalgia in later life," Pain Research and Treatment, vol. 2012, Article ID 140832, 15 pages, 2012. 
[57] D. K. Chitkara, M. A. L. van Tilburg, N. Blois-Martin, and W. E. Whitehead, "Early life risk factors that contribute to irritable bowel syndrome in adults: a systematic review," American Journal of Gastroenterology, vol. 103, no. 3, pp. 765-774, 2008.

[58] A. Roy, M. N. Janal, and M. Roy, "Childhood trauma and prevalence of cardiovascular disease in patients with type 1 diabetes," Psychosomatic Medicine, vol. 72, no. 8, pp. 833-838, 2010.

[59] R. J. Waldinger, M. S. Schulz, A. J. Barsky, and D. K. Ahern, "Mapping the road from childhood trauma to adult somatization: the role of attachment," Psychosomatic Medicine, vol. 68, no. 1, pp. 129-135, 2006.

[60] M. Fiddler, J. Jackson, N. Kapur, A. Wells, and F. Creed, "Childhood adversity and frequent medical consultations," General Hospital Psychiatry, vol. 26, no. 5, pp. 367-377, 2004.

[61] E. A. Walker, W. Katon, J. Russo, P. Ciechanowski, E. Newman, and A. W. Wagner, "Health care costs associated with posttraumatic stress disorder symptoms in women," Archives of General Psychiatry, vol. 60, no. 4, pp. 369-374, 2003.

[62] S. Habetha, S. Bleich, J. Weidenhammer, and J. M. Fegert, "A prevalence-based approach to societal costs occurring in consequence of child abuse and neglect," Child and Adolescent Psychiatry and Mental Health, vol. 6, no. 1, pp. 6-35, 2012.

[63] F. Ducrocq, G. Vaiva, O. Cottencin, S. Molenda, and D. Bailly, "Post-traumatic stress disorder, post-traumatic depression and major depressive disorder: about literature," Encephale, vol. 27, no. 2, pp. 159-168, 2001.

[64] K. T. Brady, T. K. Killeen, T. Brewerton, and S. Lucerini, "Comorbidity of psychiatric disorders and posttraumatic stress disorder," Journal of Clinical Psychiatry, vol. 61, no. 7, pp. 22-32, 2000.

[65] C. R. Brewin, B. Andrews, and J. D. Valentine, "Meta-analysis of risk factors for posttraumatic stress disorder in trauma-exposed adults," Journal of Consulting and Clinical Psychology, vol. 68, no. 5, pp. 748-766, 2000.

[66] D. Chan, A. D. Cheadle, G. Reiber, J. Unützer, and E. F. Chaney, "Health care utilization and its costs for depressed veterans with and without comorbid PTSD symptoms," Psychiatric Services, vol. 60, no. 12, pp. 1612-1617, 2009.

[67] M. Oquendo, D. A. Brent, B. Birmaher et al., "Posttraumatic stress disorder comorbid with major depression: factors mediating the association with suicidal behavior," American Journal of Psychiatry, vol. 162, no. 3, pp. 560-566, 2005.

[68] P. E. Holtzheimer III, J. Russo, D. Zatzick, C. Bundy, and P. P. Roy-Byrne, "The impact of comorbid posttraumatic stress disorder on short-term clinical outcome in hospitalized patients with depression," American Journal of Psychiatry, vol. 162, no. 5, pp. 970-976, 2005.

[69] B. L. Green, J. L. Krupnick, J. Chung et al., "Impact of PTSD comorbidity on one-year outcomes in a depression trial," Journal of Clinical Psychology, vol. 62, no. 7, pp. 815-835, 2006.

[70] Y. Lecrubier, "Posttraumatic stress disorder in primary care: a hidden diagnosis," Journal of Clinical Psychiatry, vol. 65, no. 1, pp. 49-54, 2004.

[71] L. M. McLean and R. Gallop, "Implications of childhood sexual abuse for adult borderline personality disorder and complex posttraumatic stress disorder," American Journal of Psychiatry, vol. 160, no. 2, pp. 369-371, 2003.

[72] M. Cloitre, B. C. Stolbach, J. L. Herman et al., "A developmental approach to complex PTSD: childhood and adult cumulative trauma as predictors of symptom complexity," Journal of Traumatic Stress, vol. 22, no. 5, pp. 399-408, 2009.
[73] M. Cloitre, D. W. Garvert, C. R. Brewin, R. C. Bryant, and A. Maercker, "Evidence for proposed ICD-11 PTSD and complex PTSD: a latent profile analysis," European Journal of Psychotraumatology, vol. 15, pp. 4-10, 2013.

[74] G. L. Gladstone, G. B. Parker, P. B. Mitchell, G. S. Malhi, K. Wilhelm, and M.-P. Austin, "Implications of childhood trauma for depressed women: an analysis of pathways from childhood sexual abuse to deliberate self-harm and revictimization," American Journal of Psychiatry, vol. 161, no. 8, pp. 1417-1425, 2004.

[75] J. E. Wiersma, J. G. F. M. Hovens, P. Van Oppen et al., "The importance of childhood trauma and childhood life events for chronicity of depression in adults," Journal of Clinical Psychiatry, vol. 70, no. 7, pp. 983-989, 2009.

[76] W. Lu, K. T. Mueser, S. D. Rosenberg, and M. K. Jankowski, "Correlates of adverse childhood experiences among adults with severe mood disorders," Psychiatric Services, vol. 59, no. 9, pp. 1018-1026, 2008.

[77] S. Ballesteros, V. Vitriol, R. Florenzano, A. Calderón, and A. Vacarezza, "Mujeres con depresión severa: relación entre trauma infantil y gravedad de síntomas clínicos," Revista Chilena de Neuro-Psiquiatría, vol. 45, no. 4, pp. 288-295, 2007.

[78] V. G. Vitriol, S. T. Ballesteros, R. U. Florenzano, K. P. Weil, and D. F. Benadof, "Evaluation of an outpatient intervention for women with severe depression and a history of childhood trauma," Psychiatric Services, vol. 60, no. 7, pp. 936-942, 2009.

[79] J. Coid, A. Petruckevitch, G. Feder, W.-S. Chung, J. Richardson, and S. Moorey, "Relation between childhood sexual and physical abuse and risk of revictimisation in women: a cross-sectional survey," The Lancet, vol. 358, no. 9280, pp. 450-454, 2001.

[80] J. G. Noll, P. K. Trickett, W. W. Harris, and F. W. Putnam, "The cumulative burden borne by offspring whose mothers were sexually abused as children: descriptive results from a multigenerational study," Journal of Interpersonal Violence, vol. 24, no. 3, pp. 424-449, 2009.

[81] S. Sigurdardottir and S. Halldorsdottir, "Repressed and silent suffering: consequences of childhood sexual abuse for women's health and well-being," Scandinavian Journal of Caring Sciences, vol. 27, no. 2, pp. 422-432, 2013.

[82] V. Vitriol, M. Gomberoff, and S. Ballesteros, "Relación entre trastorno por estrés postraumático de inicio tardío, abuso sexual infantil y revictimización sexual: caso clínico," Revista Médica de Chile, vol. 134, pp. 1302-1305, 2006.

[83] V. Vitriol, M. Vásquez, I. Iturria, and C. Muñoz, "Diagnóstico y abordaje de secuelas por abuso sexual infantil, en tres mujeres consultantes a un servicio de salud mental de hospital general," Revista Chilena de Neuro-Psiquiatría, vol. 45, no. 1, pp. 20-28, 2007.

[84] J. Richardson, G. Feder, S. Eldridge, W. S. Chung, J. Coid, and S. Moorey, "Women who experience domestic violence and women survivors of childhood sexual abuse: a survey of health professionals' attitudes and clinical practice," British Journal of General Practice, vol. 51, no. 467, pp. 468-470, 2001.

[85] K. Swahnberg, B. Wijma, G. Wingren, M. Hilden, and B. Schei, "Women's perceived experiences of abuse in the health care system: their relationship to childhood abuse," BJOG, vol. 111, no. 12, pp. 1429-1436, 2004.

[86] C. B. Nemeroff, C. M. Heim, M. E. Thase et al., "Differential responses to psychotherapy versus pharmacotherapy in patients with chronic forms of major depression and childhood trauma," Proceedings of the National Academy of Sciences of the United States of America, vol. 100, no. 24, pp. 14293-14296, 2003. 
[87] K. Douglas and J. Porter, "The effect of childhood trauma on pharmacological treatment response in depressed inpatients," Psychiatry Research, vol. 200, no. 2-3, pp. 1058-1061, 2012.

[88] M. J. Kaplan and N. A. Klinetob, "Childhood emotional trauma and chronic posttraumatic stress disorder in adult outpatients with treatment-resistant depression," Journal of Nervous and Mental Disease, vol. 188, no. 9, pp. 596-601, 2000.

[89] J. M. Johnstone, S. E. Luty, J. D. Carter, R. T. Mulder, C. M. A. Frampton, and P. R. Joyce, "Childhood neglect and abuse as predictors of antidepressant response in adult depression," Depression and Anxiety, vol. 26, no. 8, pp. 711-717, 2009.

[90] G. L. Klerman, M. M. Weismann, B. Rounsaville, and E. Chevron, Interpersonal Psychotherapy of Depression, Basic Books, New York, NY, USA, 1984.

[91] A. Charuvastra and M. Cloitre, "Social bonds and posttraumatic stress disorder," Annual Review of Psychology, vol. 59, pp. 301$328,2008$.

[92] M. Cloitre, C. Stovall-McClough, P. Zorbas, and A. Charuvastra, "Attachment organization, emotion regulation, and expectations of support in a clinical sample of women with childhood abuse histories," Journal of Traumatic Stress, vol. 21, no. 3, pp. 282-289, 2008.

[93] B. A. Van der Kolk, "Clinical implications of neuroscience research in PTSD," Annals of the New York Academy of Sciences, vol. 1071, pp. 277-293, 2006.

[94] S. Freud, "Repetir, recordar, reelaborar (1915)," in Obras Completas, vol. 12, Editorial Amorrortu, Buenos Aires, Argentina, 1985.

[95] S. Freud, "Más allá del principio del placer," in Obras Completas, vol. 18, Editorial Amorrortu, Buenos Aires, Argentina, 1985.

[96] B. A. Van der Kolk, "The compulsion to repeat the trauma. Reenactment, revictimization, and masochism," Psychiatric Clinics of North America, vol. 12, no. 2, pp. 389-411, 1989.

[97] V. Vitriol, A. Cancino, and S. Ballesteros, "Mujeres con depresión severa y trauma relacional temprano: una propuesta de intervención operacionalizada en los servicios de salud," Revista GPU, vol. 6, no. 4, pp. 501-510, 2010.

[98] R. V. Saveanu and C. B. Nemeroff, "Etiology of depression: genetic and environmental factors," Psychiatric Clinics of North America, vol. 35, no. 1, pp. 51-71, 2012.

[99] N. L. Talbot, Y. Conwell, M. W. O’Hara et al., "Interpersonal psychotherapy for depressed women with sexual abuse histories: a pilot study in a community mental health center," Journal of Nervous and Mental Disease, vol. 193, no. 12, pp. 847-850, 2005.

[100] M. R. H. Kessler, M. B. White, and B. S. Nelson, "Group treatments for women sexually abused as children: a review of the literature and recommendations for future outcome research," Child Abuse and Neglect, vol. 27, no. 9, pp. 1045-1061, 2003.

[101] A. Powers, K. J. Ressler, and R. G. Bradley, "The protective role of friendship on the effects of childhood abuse and depression," Depression and Anxiety, vol. 26, no. 1, pp. 46-53, 2009.

[102] M. Cloitre, K. C. Koenen, L. R. Cohen, and H. Han, "Skills training in affective and interpersonal regulation followed by exposure: a phase-based treatment for PTSD related to childhood abuse," Journal of Consulting and Clinical Psychology, vol. 70, no. 5, pp. 1067-1074, 2002.

[103] A. Cancino, V. Vitriol, and P. Riquelme, "Terremoto en Chile: evolución del estado clínico global y los síntomas posttraumáticos en una cohorte de mujeres con depresión severa en un hospital público enfrentadas al terremoto del 27 de febrero de 2010," Revista Chilena de Neuro-Psiquiatría, vol. 51, no. 1, pp. 16-24, 2013.

[104] M. Cloitre, "Effective psychotherapies for posttraumatic stress disorder: a review and critique," CNS Spectrums, vol. 14, no. 1, pp. 32-43, 2009.

[105] M. Cloitre, K. C. Stovall-McClough, K. Nooner et al., "Treatment for PTSD related to childhood abuse: a randomized controlled trial," American Journal of Psychiatry, vol. 167, no. 8, pp. 915-924, 2010.

[106] H. Kerbage and S. Richa, "Non-antidepressant long-term treatment in Post-Traumatic Stress Disorder (PTSD)," Current Clinical Pharmacology. In press. 


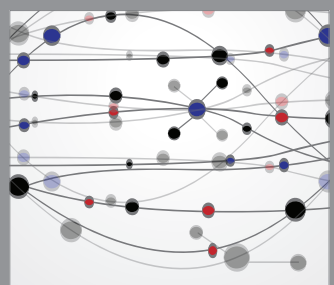

The Scientific World Journal
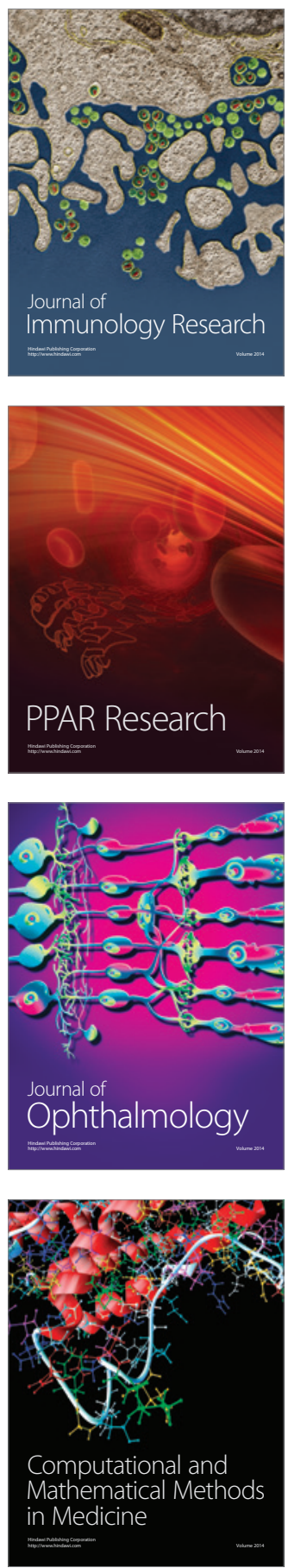

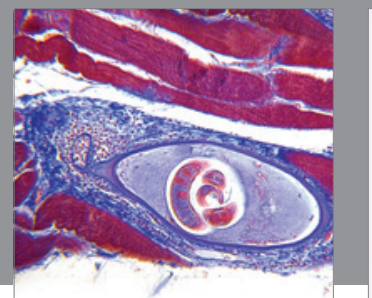

Gastroenterology

Research and Practice
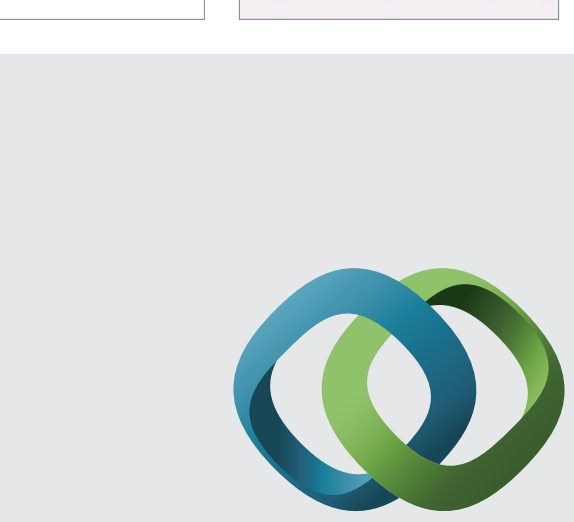

\section{Hindawi}

Submit your manuscripts at

http://www.hindawi.com
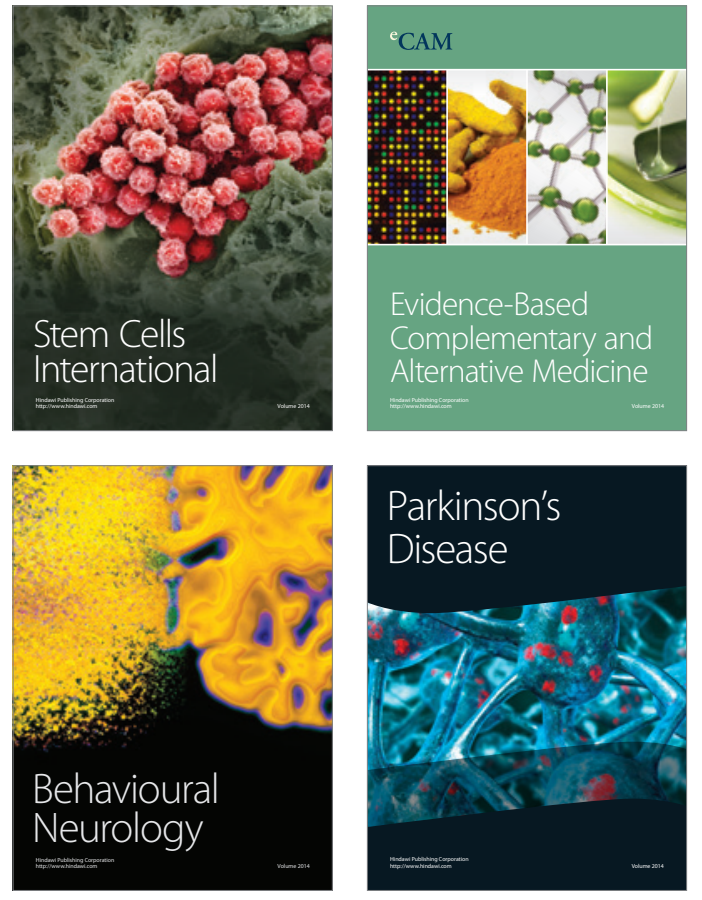
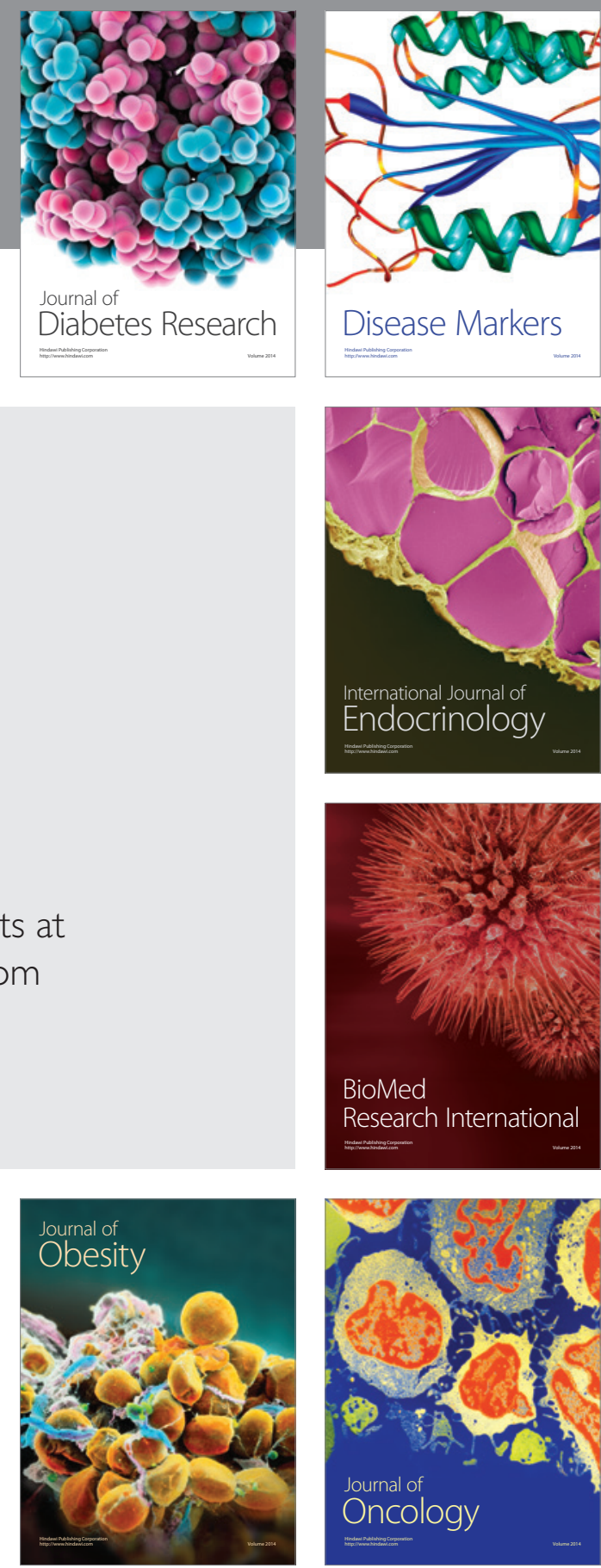

Disease Markers
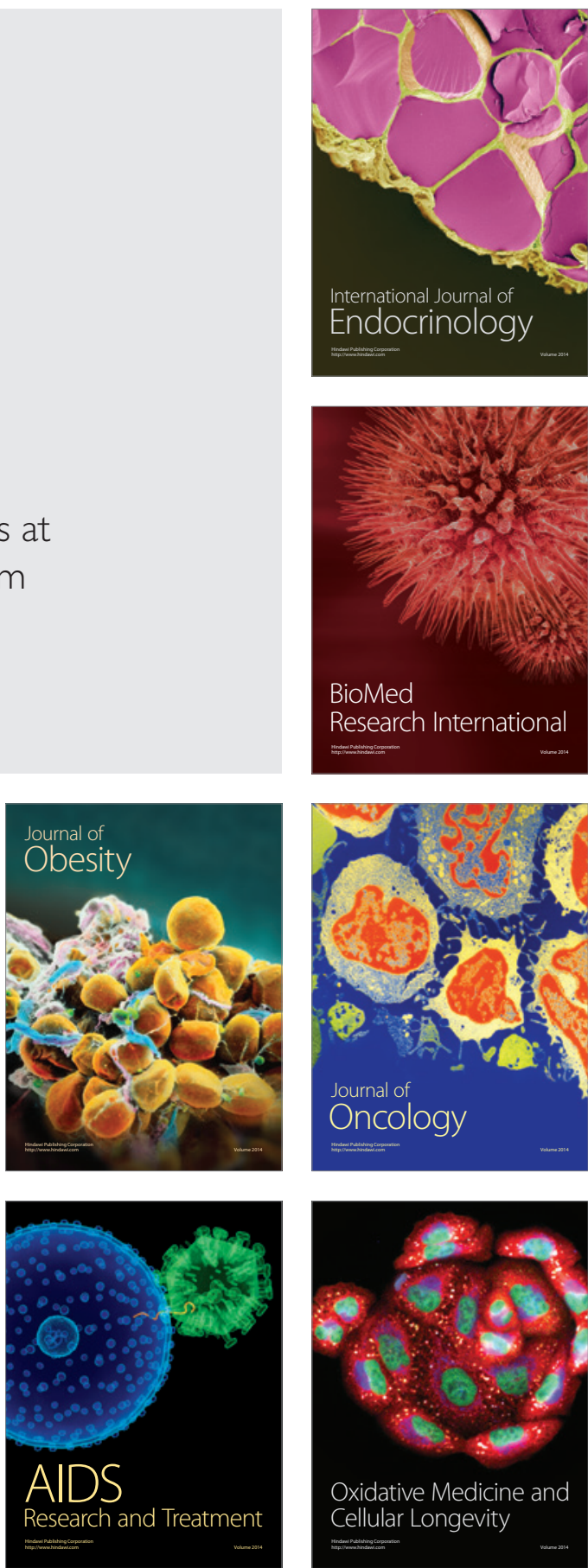